STRUCTURAL BIOLOGY ISSN 2059-7983

Keywords: obituaries; Michael Rossmann.

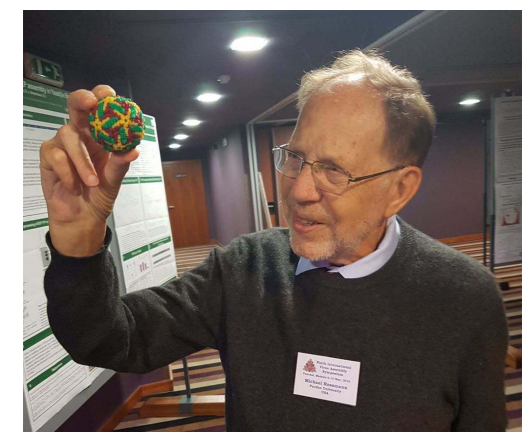

(C) 2019 International Union of Crystallography

\section{Michael G. Rossmann (1930-2019), pioneer in macromolecular and virus crystallography: scientist, mentor and friend}

\author{
Eddy Arnold, ${ }^{\mathrm{a} *}$ Hao $\mathrm{Wu}^{\mathrm{b}, \mathrm{c}}$ and John E. Johnson ${ }^{\mathrm{d}}$
}

${ }^{a}$ Center for Advanced Biotechnology and Medicine, and Department of Chemistry and Chemical Biology, Rutgers University, Piscataway, NJ 08854, USA, 'b Department of Biological Chemistry and Molecular Pharmacology, Harvard Medical School, Boston, MA 02115, USA, 'Program in Cellular and Molecular Medicine, Boston Children's Hospital, Boston, MA 02115, USA, and d Department of Integrative Structural and Computational Biology, The Scripps Research Institute, La Jolla, CA 92037, USA. *Correspondence e-mail: arnold@cabm.rutgers.edu

Michael George Rossmann, who made monumental contributions to science, passed away peacefully in West Lafayette, Indiana on 14 May 2019 at the age of 88, following a courageous five-year battle with cancer. Michael was born in Frankfurt, Germany on 30 July 1930. As a young boy, he emigrated to England with his mother just as World War II ignited. Michael was a highly innovative and energetic person, well known for his intensity, persistence and focus in pursuing his research goals. Michael was a towering figure in crystallography as a highly distinguished faculty member at Purdue University for 55 years. Michael made many seminal contributions to crystallography in a career that spanned the entirety of structural biology, beginning in the 1950s at Cambridge where the first protein structures were determined in the laboratories of Max Perutz (hemoglobin, 1960) and John Kendrew (myoglobin, 1958). Michael's work was central in establishing and defining the field of structural biology, which amazingly has described the structures of a vast array of complex biological molecules and assemblies in atomic detail. Knowledge of three-dimensional biological structure has important biomedical significance including understanding the basis of health and disease at the molecular level, and facilitating the discovery of many drugs.

\section{Education in crystallography with J. Monteath Robertson and William N. Lipscomb}

Michael had enormous impact on developing methodology for the determination of macromolecular crystal structures. His grasp of mathematics was always a strength, as he continually developed methods that would become part of the standard repertoire of macromolecular crystallographic tools. Michael obtained undergraduate degrees in mathematics and physics at the University of London. For his graduate work, he studied crystal structures of organic compounds with J. Monteath Robertson at the University of Glasgow. Following his graduate studies he was a postdoctoral fellow with William $\mathrm{N}$. Lipscomb at the University of Minnesota, pursuing structures of relatively complicated organic crystals. In his work at Minnesota, Michael wrote computer programs (in machine language at the time) for crystal structure analysis, taking advantage of the new digital computers that would revolutionize the practice of crystallography. In a lecture by Dorothy Hodgkin at the Fourth IUCr Congress in Montreal in 1957, Michael learned about exciting work on the structure determination of hemoglobin by Max Perutz at Cambridge University. Michael wrote to Max and was given an offer to join the hemoglobin structure determination team. 


\section{Beginnings of protein structure determination at Cambridge}

Michael worked closely with Max Perutz and was instrumental in elucidating the hemoglobin structure by writing the computer programs required to solve and analyze these first structures, and by calculating the Fourier maps that gave rise to the hemoglobin structure. Max had been pursuing the crystal structure of hemoglobin since the late 1930s and was a protégé of Sir Lawrence Bragg, one of the giants of crystallography who had helped to create the field of X-ray crystallography with his father, Sir William Bragg. When Michael arrived at Cambridge he began to analyze the X-ray diffraction data that Max and Ann Cullis had collected for the native hemoglobin crystals and multiple heavy-atom derivatives.

He invented methods and created computer algorithms for reliable phasing using heavy-atom isomorphous replacement and the practical determination of protein structures. While processing and analyzing the existing heavy-atom derivative datasets, he developed the difference Patterson map using squared difference coefficients $\left(\left|F_{\text {heavy }}\right|-\left|F_{\text {native }}\right|\right)^{2}$ to assist in locating the relative positions of heavy atoms in the isomorphous datasets (Rossmann, 1960). Michael also applied similar considerations to locating heavy atoms using anomalous dispersion (Rossmann, 1961) and with David Blow developed the single isomorphous replacement method (Blow \& Rossmann, 1961) and mathematical representations of combining phase information from multiple sources (isomorphous replacement, anomalous dispersion etc.) (Rossmann \& Blow, 1961). By 1959, Michael had computed a $5.5 \AA$ resolution electron-density map for hemoglobin that permitted a trace of the overall fold of this predominantly helical protein and revealed its three-dimensional relationship with myoglobin (Perutz et al., 1960).

\section{Molecular replacement has become the most common method for solving macromolecular crystal structures}

During his extraordinarily productive time at Cambridge, Michael also proposed and created the foundations for the molecular replacement method, which became the predominant approach for solving three-dimensional structures of proteins and other large biological assemblies such as complex enzymes and viruses. Michael had been fascinated with what he learned from conversations with other scientists at Cambridge, often during afternoon tea. For example, Crick and Watson had hypothesized that viruses would contain many identical protein subunits based on considerations of their limited genomic capacity (Crick \& Watson, 1956). Michael thought that the recurrence of biological structure in different environments, whether in a structure with multiple subunits (oligomeric enzymes, viruses etc.) or in different crystals, would provide the ability to phase (i.e. correctly image) crystal structures. Michael thought that this information could be used to help solve the phase problem for these otherwise intractable systems. The monumental paper that

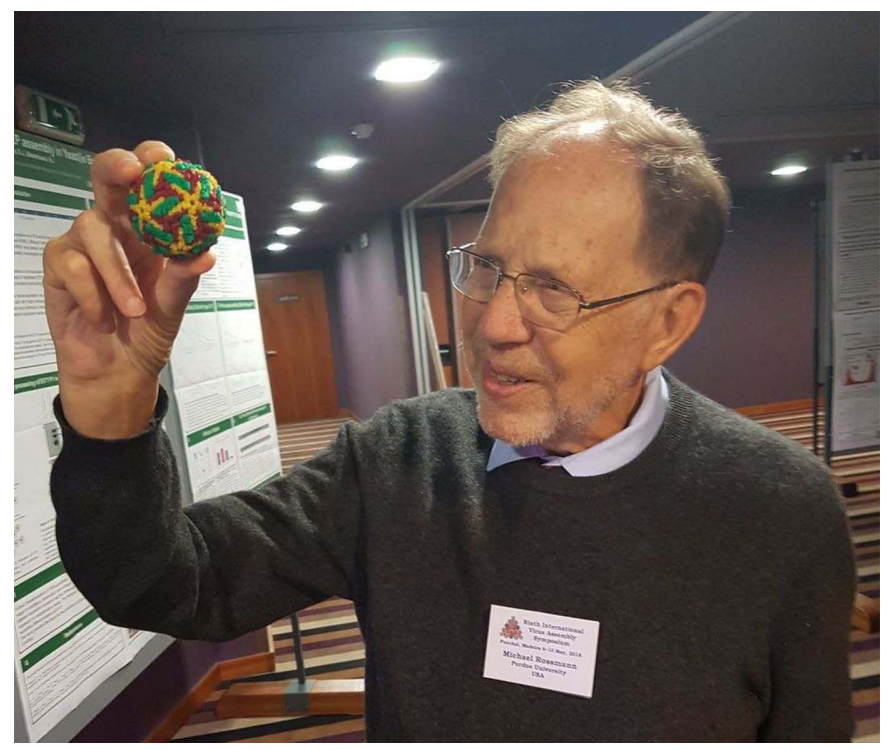

Figure 1

Michael Rossmann holding a virus model at the Ninth Virus Assembly Meeting in Madeira, Portugal, in May 2018 (photograph courtesy of Roger Castells Graells, John Innes Institute, Norwich).

Michael wrote together with David Blow (Rossmann \& Blow, 1962) presented the rotation function as a method for demonstrating the presence of rotational non-crystallographic symmetry within a crystallographic asymmetric unit and determining relative orientations. Walter Hoppe (Hoppe, 1957) had also hinted at a convolution of a similar type to find the orientation of known molecular fragments and these ideas were implemented by Robert Huber (Huber, 1965). Michael developed the rotation function based on the realization that the Patterson function would contain multiple copies of vector sets corresponding to the different orientations of the repeating units within the crystal. Rotation of the Patterson function by the angle relating the repeated objects should give 'peaks' where these vector sets were coincident, and Michael demonstrated its utility by detecting the relative orientation of the $\alpha$ and $\beta$ chains in horse hemoglobin crystals. Later he and others would develop methods for locating the position of objects in crystals, so-called translation functions. He went on to champion these ideas, while along the way determining the structures of many crucial enzymes and viruses.

Currently, the molecular replacement method is the most common approach used for solving new macromolecular structures, accounting for some $85 \%+$ of all new PDB structure depositions and the majority of all $150000+$ known structures. Molecular replacement is most frequently used to determine the orientation and location of related structures in new crystals. The search model can be the same as the new structure, or a homolog with significant three-dimensional similarity. The initial phases can then be refined using the actual sequence corresponding to the new structure using a wide variety of phasing approaches including isomorphous replacement, density modification and ultimately atomic model refinement. Non-crystallographic symmetry averaging is especially powerful in refining phases and producing 
electron-density maps with great clarity, particularly with systems that have a high degree of symmetry such as viruses, and modern computer program systems have facilitated use of these approaches by making the process more convenient.

\section{Conserved nucleotide-binding fold in glycolytic enzymes: the Rossmann fold and revolutionary concepts in molecular evolution}

Michael moved to Purdue University in 1964 to develop his own research program and apply his innovative methods to solve important biological structures. By 1971 he had determined the structure of the largest protein to date, the enzyme lactate dehydrogenase (Adams et al., 1970). Within a few years he solved another related glycolytic enzyme, lobster glyceraldehyde-3-phosphate dehydrogenase, and showed unexpectedly that a portion of the structures that bound nucleotide cofactors had highly similar structures. Based on these observations he suggested that the architecture of proteins evolved in the same way as the anatomy of animals (Buehner et al., 1973; Rossmann et al., 1974). This conserved part of protein anatomy is called the 'Rossmann fold' to recognize Michael's ingenious new idea. He had initially thought along these lines at Cambridge: when solving the structure of hemoglobin, a protein that carries oxygen in red blood cells, Michael saw that the two protein chains of hemoglobin had strong three-dimensional resemblance to each other despite lacking obvious sequence similarity, and also to myoglobin, which carries oxygen in muscle tissues. Although these concepts are very well accepted now, Michael's ideas often were greeted with resistance because they were revolutionary when suggested.

\section{Passion for viruses: technology and a plant virus structure}

A driving force behind Michael's interest in pursuing more and more complicated biological structures and in technology development was his passion to study virus structure. Michael subsequently pioneered the structure solution of entire viruses in atomic detail, requiring considerable advances in technology to handle the larger unit cells and massive amounts of crystallographic data. Following the publication of the tomato bushy stunt virus structure (Harrison et al., 1978) from Stephen Harrison's group in 1978, Michael reported the structure of Southern bean mosaic virus (Abad-Zapatero et al., 1980), and the surprising revelation that the coat protein structures of these two plant viruses shared a common protein fold, an eight-stranded $\beta$-barrel also known as a 'jelly roll' fold. This work required the development of oscillation photography for data collection, and processing and postrefinement of the intensity data measured on X-ray film (Rossmann et al., 1979; Winkler et al., 1979). Writing programs and developing efficient algorithms for location of heavy atoms in the presence of non-crystallographic symmetry and averaging of the electron density were also massive under- takings, especially given the more limited computing resources of that era.

6. The common cold virus structure: more innovations and amazing biology

Michael shifted attention to animal viruses in the early 1980s. His work gained wide attention when he reported the structure of a common cold virus in 1985, human rhinovirus 14, the first animal virus described in atomic detail (Rossmann et al., 1985). The rhinovirus structure was a landmark in terms of its biological significance, illuminating principles of viral assembly, and interactions with neutralizing antibodies, cellular receptors and antiviral drugs. Michael's career-long theme of making fundamental discoveries in molecular evolution struck once again - the coat protein structures of human rhinovirus 14 showed great similarity to the plant virus structures, in spite of having essentially no detectable sequence conservation!

The structure determination of rhinovirus itself was extraordinary, using a pioneering combination of high-intensity synchrotron radiation, high-speed supercomputing and the most convincing demonstration up to that time of phase extension using non-crystallographic symmetry averaging and reconstruction (Arnold et al., 1987). Heavy-atom phases were only available to $5 \AA$ resolution from a single $\mathrm{Au}(\mathrm{CN})_{2}$ derivative, and phase extension via 20 -fold non-crystallographic symmetry averaging and reconstruction in gradual steps to $3.5 \AA$ resolution led to a complete trace of the four chains of VP1, VP2, VP3 and VP4 in the protomeric unit. Within three weeks a complete model of the $>800$ amino acids in the icosahedral asymmetric unit had been built using a newly acquired Evans \& Sutherland computer graphics system. The phase extension was carried out to $3.0 \AA$ resolution, and the refined phases were subsequently used as observations in atomic model refinement because of their accuracy (Arnold \& Rossmann, 1988). Some of the current cryo-electron microscopy (cryo-EM) model refinements using the observed phases have adopted a similar methodological approach, where phases obtained experimentally from the EM determination are used as observations in reciprocal space-based refinement protocols. A great deal of programming was required to adapt the Rossmann laboratory software from earlier CDC6000 series computers (CDC6500 and CDC6600) to the Cyber 205 supercomputer, and many memorable adventures occurred during that process, including finding and fixing 'bugs' in the programs that sometimes may have existed since their initial implementations!

\section{Virus structures for all seasons and initial work using cryo-EM}

Following the common cold virus structure work, Michael solved the crystallographic structures of many other RNA viruses from plants and animals including polio-, coxsackie-, and cardioviruses. He also determined the crystal structures of DNA viruses including human, canine, feline and porcine 
parvoviruses. In addition, Michael solved the detailed structures of both small and large bacteriophages. To further probe biological function, Michael pursued the structures of complexes of viruses with their cellular receptors, neutralizing antibodies and small-molecule drugs. To study some of the complexes with cellular receptors and antibodies, Michael began to use cryo-EM. Tim Baker had set up an experimental facility at Purdue University for the study of virus structure by cryo-EM and, with Jack Johnson, studied interactions between plant viruses and cognate antibodies as a proof-of-concept for the study of such complexes (Wang et al., 1992). Michael and Baker used this approach to show that the ICAM-1 receptor for HRV14 bound in the canyon as predicted (Olson et al., 1993). In addition, Tom Smith and Baker studied a series of monoclonal Fab fragments attached to their cognate antigenic sites on HRV14.

\section{Cryo-EM: large and enveloped viruses including the flavivirus structures}

As many viruses cannot be crystallized easily, Michael also recognized, fairly early on, the importance of cryo-EM for structural virology. When cryo-EM investigations can be augmented by crystallographic determination of the component proteins, they produce 'pseudo atomic resolution' structures of the whole virus, a method dubbed hybrid technology that Michael helped to develop. Today, cryo-EM is capable of producing high-resolution structures providing atomic detail with suitable samples, but during the 1990s the cryo-EM technology was limited to producing structures of viruses and other assemblies at resolutions in the 10-20 $\AA$ range, and the hybrid method was the approach that could provide interpretation of interactions as the molecular level of detail. With Tim Baker, Michael was able to use the hybrid method to determine the structure of the lipid enveloped alphaviruses Ross River virus (Cheng et al., 2002) and Sindbis virus (Zhang et al., 2002). Together with virologist Richard Kuhn who had joined the Purdue structural biology group, Michael determined the structures of flaviviruses, e.g. dengue virus (Kuhn et al., 2002) and West Nile virus (Mukhopadhyay et al., 2003), and mapped their interactions with antibodies and conformational changes when subjected to acidic conditions. In the astonishing Zika virus work, he and collaborator Richard Kuhn obtained a sample of the virus in February 2016 and published the complete atomic structure in Science in April (Sirohi et al., 2016). Michael's laboratory was equipped by this time with state-of-the-art cryo-EM technology (Titan Krios and Gatan K2 Summit detector) underlying the 'resolution revolution' in EM that permits high-resolution structure determination of complex macromolecular structures from averaging of many thousands of randomly oriented single particles or viruses. As was characteristic for him throughout his research career when working on new topics and technological areas, Michael wrote computer programs to perform EM analyses including obtaining optimal fits of atomic models into cryo-EM electron-density maps. Over time, Michael also became emphatic that crystallography was 'old fashioned' and that cryo-EM was the wave of the future. But when good crystals can be obtained, there can be many advantages to solving crystal structures, especially given the extraordinary technological innovations that have occurred in this field, among which are synchrotrons, $100 \%$ quantum-efficient detectors, very powerful and flexible software packages and tremendously faster computing hardware along with massive data storage systems with rapid access.

\section{Awards, honors, recognitions, and honorary degrees}

Michael's achievements, which have been recognized by many awards, are among the most impactful contributions to the chemical and life sciences: inventing crystallographic methodology used to solve most macromolecular structures; solving virus structures and developing the methods for doing so; and suggesting that proteins could evolve, with folded domains being the fundamental evolutionary unit. Michael was a Member of the US National Academy of Sciences (1984) and the American Academy of Arts and Sciences (1978), and was a Foreign Member of the Royal Society (1996). Among his most notable awards were the Ewald Prize, Grigori Aminoff Prize, Fankuchen Award, Louisa Gross Horwitz Prize, Gairdner Foundation Award, Paul Ehrlich and Ludwig Darmstaedter Prize, Sackler Prize in Biophysics, Stein and Moore Award from the Protein Society, and three consecutive NIH MERIT Awards. He held six honorary degrees from international universities and was a Member of the National Science Board (2000-2006), having been nominated by President Bill Clinton.

\section{Crystallographic awards and contributions to education in crystallography}

Michael was especially proud that the Ewald Prize (1996), the highest award given by the IUCr only once every three years, recognized his inventions in crystallographic methodology, including the molecular replacement method. The Fankuchen Award from the American Crystallographic Association (1986) was also especially fitting because Isador Fankuchen published the first diffraction patterns from virus crystals. Together Michael and Eddy Arnold edited Volume F of the International Tables for Crystallography, which was the first volume of the series that focused on macromolecular crystallography (Rossmann \& Arnold, 2001). The first edition was published in 2001, with a second in 2012 including contributions from Daniel Himmel (Arnold et al., 2012), and a third is in preparation with the participation of Liang Tong. The third edition will be dedicated to the memory of Michael.

Michael trained a legion of scientists, including postdoctoral and graduate students who themselves have established many vibrant and productive research programs worldwide. Michael developed many close life-long friendships with his students and co-workers. Michael also played a key role in the education of young scientists in crystallography and structural biology. For example, he organized the first meeting of the International School for Crystallography in Erice, Italy, on the 
topic of macromolecular crystallography in 1976, when Dorothy Hodgkin was the Director. In 2006, Michael again organized the school on the topic of biological macromolecules and their assemblies, with Tom Blundell as Director of the School. The 2006 program included a strong representation of the field of cryo-EM, reflecting Michael's interest in using that approach to image biological structures of everincreasing complexity. The Erice school often has as many as 100 or more students at the graduate and postdoctoral level in attendance for a ten-day program that features a mix of talks on fundamental methodology and new results.

\section{Michael's family life}

Michael and his dear wife of 55 years, Audrey, had three children. In addition to son Martin, and daughters Alice and Heather, he is also survived by four grandchildren. Following Audrey's death, Michael met Karen Bogan. They were married a year ago and enjoyed great happiness together. At a Memorial Service in West Lafayette, following his death, many memories of him as a warm and influential family member, friend and mentor were shared, including his child-like curiosity about almost everything and diverse interests in exploring the natural world, both physically and intellectually.

\section{References}

Abad-Zapatero, C., Abdel-Meguid, S. S., Johnson, J. E., Leslie, A. G. W., Rayment, I., Rossmann, M. G., Suck, D. \& Tsukihara, T. (1980). Nature, 286, 33-39.

Adams, M. J., Ford, G. C., Koekoek, R., Lentz, P. J. Jr, McPherson, A. Jr, Rossmann, M. G., Smiley, I. E., Schevitz, R. W. \& Wonacott, A. J. (1970). Nature, 227, 1098-1103.

Arnold, E., Himmel, D. M. \& Rossmann, M. G. (2012). Editors. International Tables for Crystallography, Vol. F, Crystallography of Biological Macromolecules. Chichester: Wiley.

Arnold, E. \& Rossmann, M. G. (1988). Acta Cryst. A44, 270-283.

Arnold, E., Vriend, G., Luo, M., Griffith, J. P., Kamer, G., Erickson, J. W., Johnson, J. E. \& Rossmann, M. G. (1987). Acta Cryst. A43, 346361.
Blow, D. M. \& Rossmann, M. G. (1961). Acta Cryst. 14, 1195-1202.

Buehner, M., Ford, G. C., Moras, D., Olsen, K. W. \& Rossmann, M. G. (1973). Proc. Natl Acad. Sci. USA, 70, 3052-3054.

Cheng, R. H., Kuhn, R. J., Olson, N. H., Rossmann, M. G., Choi, H. K., Smith, T. J. \& Baker, T. S. (1995). Cell, 80, 621-630.

Crick, F. C. \& Watson, J. D. (1956). Nature, 177, 473-475.

Harrison, S. C., Olson, A. J., Schutt, C. E., Winkler, F. K. \& Bricogne, G. (1978). Nature, 276, 368-373.

Hoppe, W. (1957). Acta Cryst. 10, 750-751.

Huber, R. (1965). Acta Cryst. 19, 353-356.

Kuhn, R. J., Zhang, W., Rossmann, M. G., Pletnev, S. V., Corver, J., Lenches, E., Jones, C. T., Mukhopadhyay, S., Chipman, P. R., Strauss, E. G., Baker, T. S. \& Strauss, J. H. (2002). Cell, 108, 717725.

Mukhopadhyay, S., Kim, B. S., Chipman, P. R., Rossmann, M. G. \& Kuhn, R. J. (2003). Science, 302, 248.

Olson, N. H., Kolatkar, P. R., Oliveira, M. A., Cheng, R. H., Greve, J. M., McClelland, A., Baker, T. S. \& Rossmann, M. G. (1993). Proc. Natl Acad. Sci. USA, 90, 507-551.

Perutz, M. F., Rossmann, M. G., Cullis, A. F., Muirhead, H., Will, G. \& North, A. C. T. (1960). Nature, 185, 416-422.

Rossmann, M. G. (1960). Acta Cryst. 13, 221-226.

Rossmann, M. G. (1961). Acta Cryst. 14, 383-388.

Rossmann, M. G. \& Arnold, E. (2001). Editors. International Tables for Crystallography, Vol. F, Crystallography of Biological Macromolecules. Dordrecht: Kluwer Academic Publishers.

Rossmann, M. G., Arnold, E., Erickson, J. W., Frankenberger, E. A., Griffith, J. P., Hecht, H. J., Johnson, J. E., Kamer, G., Luo, M., Mosser, A. G., Rueckert, R. R., Sherry, B. \& Vriend, G. (1985). Nature, 317, 145-153.

Rossmann, M. G. \& Blow, D. M. (1961). Acta Cryst. 14, 641-647.

Rossmann, M. G. \& Blow, D. M. (1962). Acta Cryst. 15, 24-31.

Rossmann, M. G., Leslie, A. G. W., Abdel-Meguid, S. S. \& Tsukihara, T. (1979). J. Appl. Cryst. 12, 570-581.

Rossmann, M. G., Moras, D. \& Olsen, K. W. (1974). Nature (London), 250, 194-199.

Sirohi, D. Z., Chen, L., Sun, T., Klose, T. C., Pierson, M. G., Rossmann, M. G. \& Kuhn, R. J. (2016). Science, 352, 467-470.

Wang, G. J., Porta, C., Chen, Z. G., Baker, T. S. \& Johnson, J. E. (1992). Nature, 355, 275-278.

Winkler, F. K., Schutt, C. E. \& Harrison, S. C. (1979). Acta Cryst. A35, 901-911.

Zhang, W., Mukhopadhyay, S., Pletnev, S. V., Baker, T. S., Kuhn, R. J. \& Rossmann, M. G. (2002). J. Virol. 76, 11645-11658. 